\title{
Resolution of Viable and \\ Membrane-Compromised Free \\ Bacteria in Aquatic Environments by Flow Cytometry
}

\author{
Gérald Grégori, ${ }^{1,2,4}$ Michel Denis, ${ }^{2}$ Sergio Sgorbati, ${ }^{3}$ and Sandra Citterio ${ }^{3}$ \\ ${ }^{1}$ Purdue University Cytometry Laboratories, West Lafayette, Indianna \\ ${ }^{2}$ Aix-Marseille Université, CNRS, IRD, Universite de Toulon, Mediterranean Institute of \\ Oceanography (MIO), Marseille, France \\ ${ }^{3}$ Università di Milano-Bicocca, Milan, Italy \\ ${ }^{4}$ Corresponding author: gerald.gregori@mio.osupytheas.fr
}

\begin{abstract}
In aquatic environments, free heterotrophic bacteria play an extremely important role due to their high biomass, wide panel of metabolisms, and ubiquity, as well as the toxicity of certain species. This unit presents a nucleic-acid doublestaining protocol (NADS) for flow cytometry that can distinguish fractions of viable, damaged, or membrane-compromised cells within the free-bacterial community. The NADS protocol is based on the simultaneous utilization of two nucleic acid stains-membrane-permeant SYBR Green and membraneimpermeant propidium iodide (PI). The efficiency of the double staining on fresh samples is magnified by the FRET from SYBR Green to PI when both are bound to the nucleic acids. Full quenching of SYBR Green fluorescence by PI identifies cells with a compromised membrane, partial quenching indicates cells with a slightly damaged membrane, and lack of quenching characterizes cells with an intact membrane. Samples do not require any pretreatment and this protocol can be performed almost anywhere. (C) 2018 by John Wiley \& Sons, Inc.
\end{abstract}

Keywords: flow cytometry $\bullet$ microbiology $\bullet$ NADS

\section{How to cite this article:}

Grégori, G., Denis, M., Sgorbati, S., \& Citterio, S. (2018).

Resolution of viable and membrane-compromised free bacteria in aquatic environments by flow cytometry. Current Protocols in

Cytometry, 85, e42. doi: 10.1002/cpcy.42

Cellular viability is a key parameter in the study of aquatic microbial assemblages and their relationships with the natural environment because it allows one to correlate total activities measured by a global method with the only fraction of active cells responsible for these activities (Gasol, Zweifel, Peters, Fuhrman, \& Hagström, 1999). Membrane integrity is one of the main criteria generally accepted to characterize a living cell and to distinguish it from a dead or damaged one. Membranes isolate the cell from the exterior medium, regulate ion or molecule exchanges between them, and are indispensable to the establishment of the proton electrochemical potential difference driving ATP synthesis at the bioenergetic-membrane level during oxidative phosphorylation (Mitchell, 1961; Nicholls, 1982).

In aquatic environments, free heterotrophic bacteria play an important role because of their high biomass, wide panel of metabolisms, and ubiquity, as well as the toxicity 
of certain species (Porter, 1996). They are extremely small with relatively low amounts of cell constituents (Swan et al., 2013).

Bacteria are responsible for most of the mineralization of organic matter in bodies of water, and the determination of their abundance and biomass are basic parameters in related investigations (Kirchman, Suzuki, Garside, \& Ducklow, 1991; Pomeroy, 1984; Robertson \& Button, 2001). Although determination of the total abundance of bacteria is routinely performed (Hobbie, Daley, \& Jasper, 1977; Kogure, Simidu, \& Taga, 1979; Porter, Diaper, Edwards, \& Pickup, 1995), quantification of the viable fraction is not easily achieved. This unit presents a nucleic-acid double-staining protocol (NADS) for flow cytometry that can distinguish fractions of viable, damaged, or membranecompromised cells within the marine or freshwater free-bacterial community, while distinguishing them from debris. Flow cytometry is particularly suited for analysis of aquatic bacteria because it is able to perform rapid multiparametric analysis on individual cells at cell numbers representative of natural environments (Trousselier, Courties, \& Vaquer, 1993).

Since heterotrophic bacteria do not contain natural photosynthetic pigments and are not autofluorescent, staining must be performed to discriminate and enumerate these bacteria by flow cytometry (Marie, Partensky, Vaulot, \& Brussaard, 2001). Some external cell structures may also prevent the fluorochromes from reaching their cellular target (Gasol et al., 2000). The NADS protocol is based on the simultaneous utilization of two nucleic acid stains-SYBR Green and PI. SYBR Green (I or II) is a membranepermeant dye (Haugland, 1998), whereas PI is membrane impermeant (Jones \& Senft, 1985; López-Amorós, Castel, Comas-Riu, \& Vives-Rego, 1997; Sgorbati, Barbesti, Citterio, Bestetti, \& De Vecchi, 1996; Williams et al., 1998). Both are readily excited by the blue line from an argon laser or an arc lamp, the excitation sources generally found in benchtop analytical flow cytometers. The efficiency of the double staining is magnified by the FRET from SYBR Green to PI when both are bound to the nucleic acids (Barbesti et al., 2000), where the green fluorescence of SYBR Green is quenched by PI (for more details on FRET, refer to Szöllősi, Damjanovich, \& Mátyus (2001)). According to the FRET phenomenon, full quenching of SYBR Green fluorescence by PI will identify cells with compromised membranes fully permeable to PI, which will result in cells with red-only fluorescence. Partial quenching will indicate cells with a slightly damaged membrane that allows a small amount of PI to penetrate, which will result in cells with both red and green fluorescence. Lack of quenching will characterize cells with an intact membrane stained only by SYBR Green and are identified as viable by their green-only fluorescence. Figure 1 displays an example of this cluster resolution for an E. coli culture sample. This approach, originally described by Barbesti et al. (2000) for cultured bacteria, has been adapted to bacteria from fresh and marine waters (Grégori et al., 2001). For marine samples, SYBR Green II is preferred over SYBR Green I because it shows higher fluorescence intensity (Lebaron, Parthuisot, \& Catala, 1998).

Samples do not require any pretreatment and this protocol can be performed either on board a ship or in the laboratory. Samples must not be fixed to keep cells alive. The different clusters of bacteria-i.e., intact membranes (viable), damaged membranes, and compromised membranes-present in natural marine samples are discriminated on the basis of the green and red fluorescence of the cells after staining. Analogous fluorescence quenching could be achieved by using Hoechst dyes over SYBR Green (Lebaron et al., 1998; Nebe-von Caron \& Badley, 1995); however, those fluorochromes require ultraviolet excitation, which, in general, necessitates the use of more costly flow cytometers. 


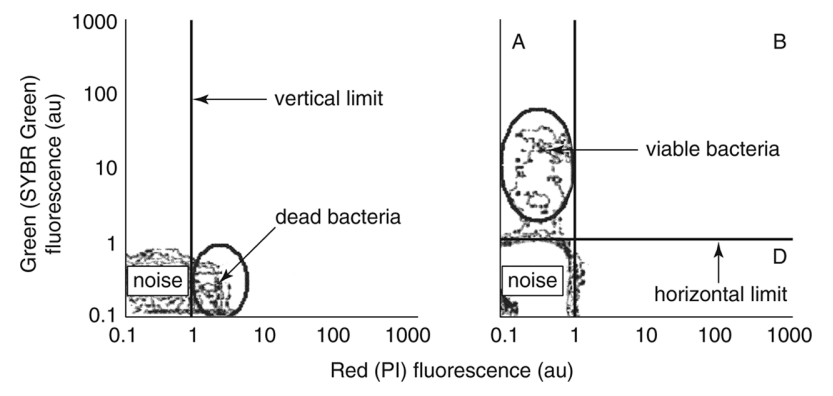

Figure 1 Determination of the $A, B$, and $D$ quadrants used to resolve viable, membranedamaged, and membrane-compromised bacteria (dead cells), respectively, on a green-versus red-fluorescence histogram. On the left, positioning of the vertical limit between red-fluorescing dead bacteria and the background noise of an ozone-treated sample. On the right, positioning of the horizontal limit between green-fluorescing viable bacteria and background noise in an untreated sample containing mainly viable bacteria.

\section{Materials}

Natural fresh- or seawater samples

SYBR Green I (fresh water) or II (seawater) working solution (see recipe)

Fresh water or seawater (filtered through a $0.2-\mu \mathrm{m}$ filter)

Cells killed by paraformaldehyde fixation, heat, or ozone treatment

Freshly harvested cells: freshly harvested natural sample with $>95 \%$ viability or sample from a bacterial culture in exponential growth phase

$1 \mathrm{mg} / \mathrm{ml}$ propidium iodide (PI, Molecular Probes), store $\leq 1$ month at $4^{\circ} \mathrm{C}$ in the dark

10\% bleach: dilute standard bleach (5\% sodium hypochlorite) 1:10 in water

$70 \%$ ethanol

Sheath fluid: distilled water passed through a $0.2-\mu \mathrm{m}$ filter

$100-\mu \mathrm{m}$ filters

$12 \times 75-\mathrm{mm}$ tubes, sterile

Vortexer

Flow cytometer with 488-nm argon laser or arc lamp and filters: $525 \pm 15$-nm (green) fluorescence and $>650-\mathrm{nm}$ (red) fluorescence

NOTE: All water, including fresh water or seawater used to dilute samples and used to prepare solutions, should be passed through a $0.2-\mu \mathrm{m}$ filter prior to use.

\section{Stain cells}

1. Filter natural fresh- or seawater samples through a $100-\mu \mathrm{m}$ filter to avoid clogging flow cytometer.

2a. For natural freshwater samples: Add $20 \mu \mathrm{l}$ SYBR Green I working solution to $1.980 \mathrm{ml}$ freshwater sample in a sterile $12 \times 75-\mathrm{mm}$ tube and vortex. In the same manner, also stain three controls:

i. $1.980 \mathrm{ml}$ water (dye background levels)

ii. Cells killed by paraformaldehyde fixation, heat, or ozone treatment (negative control)

iii. Freshly harvested cells (positive control)

2b. For natural seawater samples: Add $20 \mu \mathrm{l}$ SYBR Green II working solution to $1.980 \mathrm{ml}$ seawater sample in a sterile $12 \times 75-\mathrm{mm}$ tube and vortex. In the same manner, also stain three controls:

i. $1.980 \mathrm{ml}$ seawater (dye background levels) 
ii. Cells killed by paraformaldehyde fixation, heat, or ozone treatment (negative control)

iii. Freshly harvested cells (positive control).

The original 10,000 $\times$ concentration of dye has been reduced to $1 \times$ for both types of sample.

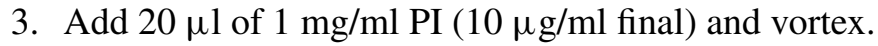

4. Incubate $30 \mathrm{~min}$ at room temperature in the dark.

\section{Calibrate flow cytometer}

5. Run the water-only sample on a flow cytometer to localize the background noise due to the dyes and adjust the detection threshold to it.

6. Resolve viable, membrane-damaged, and membrane-compromised bacteria by defining three quadrants from the background noise limits as follows:

a. Run the negative (dead) control with all parameters set on logarithmic scale.

b. Adjust the PMT voltages as necessary to ensure that red-fluorescent cells $(>620 \mathrm{~nm})$ are to the right-hand side of the display, and that their green fluorescence ( 515 to $530 \mathrm{~nm}$ ) is as weak as possible.

Position the vertical axis of the quadrant at the limit between noise and dead cells (Fig. 1).

When the NADS protocol was defined, the typical settings on the Cytoron Absolute Count instrument (Ortho Diagnostic Systems) were FS $=60$ (/255), SS $=60$ (/255), green $P M T=80(/ 255)$, orange $P M T=100(/ 255)$, and red $P M T=80(/ 255)$. While this instrument was very sensitive, it is no longer produced or distributed.

Typical settings on a flow cytometer used in aquatic sciences, the FACSCalibur (BD biosciences), are $S S=430$, green $P M T=450$, and red $P M T=540$ (Gasol et al., 2016).

Another advantage of the NADS protocol is that it can readily be used on most flow cytometers. Most flow cytometers collect:

i. Green fluorescence (GF) with a band-pass filter centered at $530 \mathrm{~nm}$. This channel is sometimes labeled as FITC(fluorescein isothiocyanate), or FL1.

ii. Orange fluorescence collected at $585 \mathrm{~nm}$. This channel is sometimes labeled PE(phycoerythrin), or FL2.

iii. Red fluorescence centered at $\sim 650 \mathrm{~nm}$. This channel is sometimes refered as PerCP (peridininchlorophyll protein complex), or FL3.

Instruments where detectors are by default labeled FL1, FL2, FL3, etc., follow, in most cases, the sequence green, orange, and red fluorescence according to their wavelengths (from shortest to longest). However, it is recommended to customize the names of the detectors to better fit the experimental set-up with the names of the fluorescent molecules responsible for the fluorescences. This allows data interpretation and comparison (with other instruments) much easier.

7. Run the positive (live) control. If necessary, adjust the PMT voltages to ensure that the green-fluorescent cells $(525 \mathrm{~nm})$ are to the upper-left side of the display and that their red fluorescence signal is as weak as possible. Position the horizontal axis of the quadrant at the limit between noise and viable cells (Fig. 1).

\section{Analyze and resolve viable, membrane-damaged, and membrane-compromised} bacteria

8. Analyze bacterial samples on the flow cytometer using the settings determined by the calibration steps. 
9. Record the percentages, numbers, or abundances of viable (green only; upperleft quadrant), membrane-damaged (green and red; upper-right quadrant), and membrane-compromised (red only; bottom-right quadrant) bacteria (Fig. 1). If the sample is too concentrated, dilute with fresh water or seawater as appropriate.

10. Clean cytometer by running successive volumes of $10 \%$ bleach, $70 \%$ ethanol, and sheath fluid until $<1$ events/sec are detectable.

\section{REAGENTS AND SOLUTIONS \\ SYBR Green I or II working solution}

In a $1.5-\mathrm{ml}$ microcentrifuge tube, dilute $10 \mu \mathrm{l} \mathrm{SYBR}$ Green I or $100 \mu 1 \mathrm{SYBR}$ Green II (Molecular Probes) in 990 or $900 \mu 1$ water, respectively. Store $\leq 1$ month at $4^{\circ} \mathrm{C}$ in the dark.

\section{COMMENTARY}

\section{Background Information}

To better understand the function of the microbial ecosystem, it is necessary to investigate the different activities of the microorganisms at the cellular level. Usually, bulk activity measurements refer to total counts and imply the involvement of all cells. This is not correct for natural samples because total counts may include ghost, dead, or damaged cells (Gasol et al., 1999; Zweifel \& Hagström, 1995). It is therefore crucial to quantify the amounts of both viable and dead cells. The nucleic-acid double-staining (NADS) protocol developed by Barbesti and co-workers (Barbesti et al., 2000) for cultured bacteria in fresh water, and was adapted to natural samples from fresh and marine environments (Grégori et al., 2001), was developed with this goal in mind. This protocol specifically addresses membrane integrity, which is a widely accepted criterion for viability (Joux \& Lebaron, 2000; Nebe-von Caron \& Badley, 1995). The general cell physiological condition can be addressed thanks to the membrane (Tyndall, Hand, Mann, Evans, \& Jernigan, 1985). The loss of membrane integrity results in the collapse of cellular energetics and active transports, quickly leading to cell death (Nebe-von Caron \& Badley, 1995). The principle of the NADS protocol described in this unit is based on the excitation energy transfer from an excited donor (SYBR Green) to an acceptor molecule (PI). This fluorescence resonance energy transfer (FRET) occurs when the distance between nucleic acidbound molecules (PI and SYBR Green) is $<70 \AA$ because the emission spectrum of SYBR Green (maximum emission at $520 \mathrm{~nm}$ ) covers the absorption spectrum of PI (maximum absorption at $535 \mathrm{~nm}$ ). Thus, on the one hand, red-only fluorescing bacteria and cells emitting both green and red fluorescence represent the fractions of dead and damaged membrane bacteria, respectively. On the other hand, green-only fluorescing bacteria represent the fraction of viable cells with preserved membrane integrity (Fig. 2).

Since the initial publication of this unit, several studies $(>120)$ have used the NADS method in several cases where bacterioplankton is faced with either typical laboratory death-causing factors or natural mortality. It has been proven that its performance can be applied not only in surface samples, but also along vertical profiles, down to the mesopelagic zone (Falcioni, Papa, \& Gasol, 2008).

Based on the literature already published, the NADS protocol can be considered a robust tracer of natural heterotrophic prokaryote mortality (by evidence of damaged membranes) and can provide information on its temporal and spatial variations.

\section{Critical Parameters}

\section{Flow cytometer calibration}

It is always innocuous to keep the data rate $<1000$ particles/sec (Gasol \& Del Giorgio, 2000). Analyze the sample, adjusting the flow rate and/or the cell concentration (by dilution) to avoid coincidence and saturation of the flow cytometer. Typically, the authors run samples for $60 \mathrm{sec}$ at a flow rate of $10 \mu \mathrm{l} / \mathrm{min}$ and maintain a data rate $<1000 / \mathrm{sec}$ by diluting samples if necessary. If this frequency is not exceeded, it is recommended to dilute sample to $2 \times, 5 \times$, or $10 \times$ with filtered sample water to avoid any damage to cells. It is not necessary to add additional dye solution. Once the stains have linked to the nucleic acids of the cells prior to sample dilution, the molecules remain in the cell. Only unbound molecules (i.e., still in suspension) will dilute with the filtered water added to the sample. 


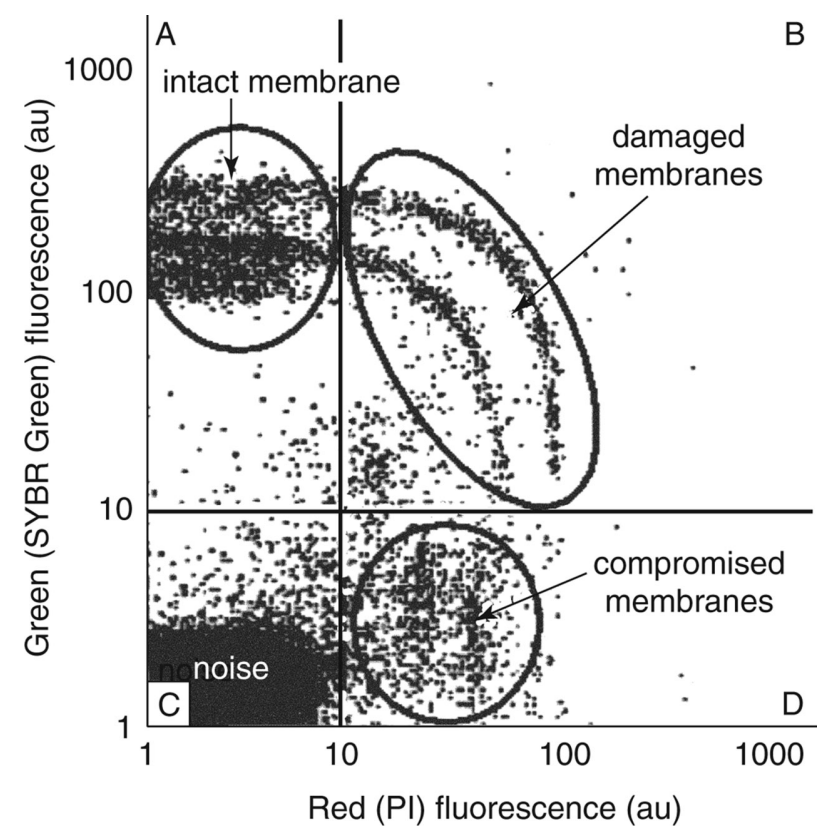

Figure 2 Application of the NADS protocol to a sample containing two different E. coli cultures. Flow cytometric analysis yields this typical cytogram characterizing cells by their fluorescence. Quadrant A includes green-fluorescent cells stained by SYBR Green only and identified as viable because membrane integrity prevents uptake of PI. Quadrant B contains green-plus redfluorescent cells stained by both SYBR Green and PI and identified as membrane-damaged cells because they enable various amounts of PI to penetrate the cell and bind to nucleic acid, inducing a corresponding increase of red fluorescence and decrease of green fluorescence, depending on the extent of FRET from SYBR Green to PI. Quadrant D includes red-fluorescent cells, which are identified as dead because the total quenching of SYBR Green fluorescence by PI reveals the presence of highly compromised membranes. Background noise is confined to quadrant C. Note that with the NADS protocol it is possible to distinguish the two $E$. coli cultures by their relative nucleic-acid content.

\section{Sample double staining}

The NADS protocol is based on a FRET mechanism between PI and SYBR Green I or II; therefore, it is important to simultaneouldy double stain each sample. Falcioni et al. (2008) reported that incubation with a single dye first would end up with results difficult to interpret.

\section{Threshold limit}

Set the discriminator to green and red fluorescence if possible (e.g., Cytoron Absolute Count flow cytometer) or on the FS or SS signals. Adjust the threshold to the background noise to improve the signal-tonoise ratio to better resolve the different clusters of bacteria and avoid instrument saturation.

\section{Preserving sample}

Determination of bacterial viability with the NADS protocol is performed only on fresh natural samples. The samples must not be fixed, but must be analyzed as soon as possible after collection. Because the analyses generally must be done in the laboratory, the authors suggest keeping samples in the dark and cold $\left(4^{\circ} \mathrm{C}\right)$ during transport to preserve freshness.

\section{Troubleshooting}

\section{Optimal dye concentrations}

In natural samples containing insufficient concentrations of bacteria (i.e., $<0.5 \times 10^{6}$ cells $/ \mathrm{ml}$ ), the background fluorescence of SYBR Green dyes and PI can be high enough to affect signal quality. To resolve this problem, it is necessary to adapt the concentrations of the fluorescent probes to that of bacteria by decreasing the added amount of dye working solution. For example, a final PI concentration of $1 \mu \mathrm{g} / \mathrm{ml}$ and a final dilution of 1/100,000 (v/v) for the SYBR Green I commercial solution are optimal for freshwater samples with $<0.5 \times 10^{6} \mathrm{bacteria} / \mathrm{ml}$. For more concentrated samples (up to $20 \times 10^{6}$ bacteria $/ \mathrm{ml}$ ), $10 \mu \mathrm{g} \mathrm{PI} / \mathrm{ml}$ and a final dilution of $1 / 10,000$ $(\mathrm{v} / \mathrm{v})$ of SYBR Green I or $1 / 1000(\mathrm{v} / \mathrm{v})$ of 
SYBR Green II have found to be best for bacterial cultures.

Falcioni et al. (2008) suggested that the ideal set of concentrations for PI and SYBR Green may vary depending upon the amount and severity of the mortality induced on the bacteria. In this study, it was reported that concentrations in the range of 5 to $20 \mu \mathrm{g} / \mathrm{ml}$ of propidium iodide, equivalent to a $10 \times$ concentration of SYBR green I, would be optimal for detecting simultaneously "live" (green-only cells) and "dead" (red-only cells) bacteria.

This showed that working with a commercial kit (such as the BacLight kit), where dyes are present in predefined concentrations, is less efficient than combining two separate dyes, with concentrations adapted by the user to fit the sample conditions.

\section{Instrument sterility}

The $0.2-\mu \mathrm{m}$ filtered distilled water used as the sheath fluid ensures the sterility of the flow cytometer and minimizes background particlescatter noise. Nevertheless, it is also important to clean the flow cytometer when the analyses are finished in order to remove residual bacteria or dye molecules from the fluidic system. The authors accomplish this by running the following solutions through the flow cytometer: (1) $10 \%$ bleach solution, (2) $70 \%$ ethanol solution, and (3) $0.2-\mu \mathrm{m}$ filtered distilled water. The flow cytometer is considered clean when the detection rate is $<1$ event/sec.

\section{Anticipated Results}

The NADS protocol is an assay based on analytical flow cytometry that allows one to distinguish viable from membrane-damaged and membrane-compromised bacteria and to sort out noise and debris. Viable cells include both active (e.g., measurable metabolic activity) and inactive states (e.g., lack of enzyme activity in nutrient-depleted environments; Nebe-von Caron \& Badley, 1995). This protocol should not be considered a strict live/dead assay, but rather as a proxy whose efficiency depends on the characteristics (cell type, physiologic state, and so on) of the cells occurring in natural samples where several populations in different physiologic and cytostructural terms can be simultaneously encountered. This large heterogeneity of bacteria in aquatic samples, where most of the species are still unknown, is the main limitation to the NADS assay as well as to other protocols using fluorochromes. Some unknown species may not be consistent with observations made thus far regarding bacterial mem- brane permeability with respect to the fluorescent probes in use. Addressing membrane integrity, the NADS protocol provides resolution of bacteria into viable (active or inactive), membrane-damaged, and membranecompromised groups, but other complementary approaches are needed to independently demonstrate the presence of specific activity or metabolism, as well as the capacity of a cell to undergo division (Lloyd and Hayes; 1995; McFeters et al., 1995; Porter, Deere, Pickup, \& Edwards, 1996; Grégori et al., 2001).

\section{Time Considerations}

The NADS protocol can be achieved in $<1 \mathrm{hr}$ and yields both quantitative (i.e., cell abundance) and qualitative (i.e., viable, membrane-damaged, and membranecompromised bacteria; nucleic acid content) information. This protocol is compatible with routine sampling and analyses and with the high-frequency sampling required to perform spatial or temporal monitoring of bacteria in aquatic environments. High-frequency sampling is not feasible with other methods that are much more time-consuming than flow cytometry, such as epifluorescence microscopy and acridine-orange or DAPI staining on membrane filters (Hobbie et al., 1977; Zimmerman \& Meyer-Reil, 1974).

\section{Acknowledgements}

The authors wish to acknowledge the support of the French-Italian Integrated Action Program "GALILEE" and of the Council of the Provence-Alpes-Côte d'Azur Region. The authors would also like to acknowledge Sam Duncan, who provided E. coli cultures.

\section{Literature Cited}

Barbesti, S., Citterio, S., Labra, M., Baroni, M. D., Neri, M. G., \& Sgorbati, S. (2000). Two and three color fluorescence flow cytometric analysis of immunoidentified viable bacteria. Cytometry, 40, 214-218. doi: 10.1002/ 1097-0320(20000701)40:3\%3c214::AIDCYTO6\%3e3.0.CO;2-M.

Falcioni, T., Papa, S., \& Gasol, J. M. (2008). Evaluating the flow cytometric nucleic acid double staining protocol (NADS) in realistic planktonic bacterial death situations. Applied and Environmental Microbiology, 74, 1767-1779. doi: 10.1128/AEM.01668-07.

Gasol, J. M. \& Del Giorgio, P. A. (2000). Using flow cytometry for counting natural planktonic bacteria and understand the structure of planktonic bacterial communities. Scientia Marina, 64, 197-224. doi: 10.3989/scimar.2000.64n2197.

Gasol, J. M., Zweifel, U. L., Peters, F., Fuhrman, J. A., \& Hagström, A. (1999). Significance of size and nucleic acid content heterogeneity as 
measured by flow cytometry in natural planktonic bacteria. Applied and Environmental Microbiology, 65, 4475-4483.

Grégori, G., Citterio, S., Ghiani, A., Labra, M., Sgorbati, S., Brown, S., \& Denis, M. (2001). Resolution of viable and membranecompromised bacteria in freshwater and marine waters based on analytical flow cytometry and nucleic acid double staining. Applied and Environmental Microbiology, 67, 4662-4670. doi: 10.1128/AEM.67.10.4662-4670.2001.

Haugland, R. P. (1998). Handbook of Fluorescent Probes and Research Chemicals. Eugene, Or.

Hobbie, J. E., Daley, R. J., \& Jasper, S. (1977). Use of nuclepore filters for counting bacteria by fluorescence microscopy. Applied and Environmental Microbiology, 33, 1225-1228.

Jones, K. H. \& Senft, J. A. (1985). An improved method to determine cell viability by simultaneous staining with fluorescein diacetatepropidium iodide. Journal of Histochemistry and Cytochemistry, 33, 77-79. doi: 10.1177/ 33.1.2578146.

Joux, F. \& Lebaron, P. (2000). Use of fluorescent probes to assess physiological functions of bacteria at single-cell level. Microbes and Infection, 2, 1523-1535. doi: 10.1016/S12864579(00)01307-1.

Kirchman, D. L., Suzuki, Y., Garside, C., \& Ducklow, H. W. (1991). High turnover rates of dissolved organic carbon during a spring phytoplankton bloom. Nature, 352, 612-614. doi: $10.1038 / 352612 \mathrm{a} 0$.

Kogure, K., Simidu, U., \& Taga, N. (1979). A tentative direct microscopic method for counting living marine bacteria. Canadian Journal of Microbiology, 25, 415-420. doi: 10.1139/m79-063.

Lebaron, P., Parthuisot, N., \& Catala, P. (1998). Comparison of blue nucleic acid dyes for flow cytometric enumeration of bacteria in aquatic systems. Applied and Environmental Microbiology, 64, 1725-1730.

Lloyd, D. \& Hayes, A. J. (1995). Vigor, vitality and viability of microorganisms. FEMS Microbiology Letters, 133, 1-7. doi: 10.1111/j.15746968.1995.tb07852.x.

López-Amorós, R., Castel, S., Comas-Riu, J., \& Vives-Rego, J. (1997). Assessment of E. coli and Salmonella viability and starvation by confocal laser microscopy and flow cytometry using Rhodamine 123, DiBAC4(3), propidium iodide and CTC. Cytometry, 29, 298-305. doi: 10.1002/(SICI)1097-0320(19971201)29:4\%3c 298::AID-CYTO6\%3e3.0.CO;2-6.

Marie, D., Partensky, F., Vaulot, D., \& Brussaard, C. (2001). Enumeration of phytoplankton, bacteria, and viruses in marine samples. Current Protocols in Cytometry, 1, 11.11.1-11.11.15. doi: 10.1002/0471142956.cy1111s10.

McFeters, G. A., Yu, F. P., Pyle, B. H., \& Stewart, P. S. (1995). Physiological assessment of bacteria using fluorochromes. Journal of Microbiological Methods, 21, 1-13. doi: 10.1016/0167-7012(94)00027-5.
Mitchell, P. (1961). Coupling of phosphorylation to electron and hydrogen transfer by chemiosmotic type mechanism. Nature, 191, 144-148. doi: 10.1038/191144a0.

Nebe-von Caron, G. \& Badley, R. A. (1995). Viability assessment of bacteria in mixed populations using flow cytometry. Journal of Microscopy, 179, 55-66. doi: 10.1111/j.1365-2818.1995.tb03612.x.

Nicholls, D. G. (1982). Bioenergetics. An Introduction to the Chemiosmotic Theory. Academic Press. London.

Pomeroy, L. R. (1984). Significance of microorganisms in carbon and energy flow in marine ecosystems. In Current Perspectives in Microbial Ecology (pp. 405-411). In M. J. Klug \& C. A. Reddy (eds.), Washington, D.C.

Porter, J., Diaper, J., Edwards, C., \& Pickup, R. (1995). Direct measurements of natural planktonic bacterial community viability by flow cytometry. Applied and Environmental Microbiology, 61, 2783-2786.

Porter, J., Deere, D., Pickup, R., \& Edwards, C. (1996). Fluorescent probes and flow cytometry new insights into environmental bacteriology. Cytometry, 23, 91-96. doi: 10.1002/(SICI) 1097-0320(19960201)23:2\%3c91::AID-CYTO 1\%3e3.0.CO;2-O.

Robertson, B. R. \& Button, D. K. (2001). Determination of bacterial biomass from flow cytometric measurements of forward light scatter intensity. Current Protocols in Cytometry, 1, 11.9.1-11.9.10. doi: 10.1002/0471142956. cy1109s09.

Sgorbati, S., Barbesti, S., Citterio, S., Bestetti, G., \& De Vecchi, R. (1996). Characterization of number, DNA content, viability and cell size of bacteria from natural environments using DAPI PI dual staining and flow cytometry. Minerva Biotec, 8, 9-15.

Swan, B. K., Tupper, B., Sczyrba, A., Lauro, F. M., Martinez-Garcia, M., González, J. M., ... Stepanauskas, R. Prevalent genome streamlining and latitudinal divergence of planktonic bacteria in the surface ocean. Proceedings of the National Academy of Sciences of the United States of America, 110, 11463-11468. doi: 10.1073/pnas.1304246110.

Szöllősi, Damjanovich, S., \& Mátyus, L. (2001). Principles of resonance energy transfer. Current Protocols in Cytometry, 1, 1.12.1-1.12.13. doi: 10.1002/0471142956.cy0112s09.

Tyndall, R. L., Hand, Jr, R. E., Mann, R. C., Evans, C., \& Jernigan, R. (1985). Application of flow cytometry to detection and characterization of Legionella spp. Applied and Environmental Microbiology, 49, 852-857.

Trousselier, M., Courties, C., \& Vaquer, A. (1993). Recent applications of flow cytometry in aquatic microbial ecology. Biology of The Cell, 78, 111121. doi: 10.1016/0248-4900(93)90121-T.

Williams, S. C., Hong, Y., Danavall, D. C. A., Howard-Jones, M. H., Gibson, D., Frisher, M. E., \& Verity, P. G. (1998). Distinguishing 
between living and nonliving bacteria evolution of the vital stain propidium iodide and its combined use with molecular probes in aquatic samples. Journal of Microbiological Methods, 23, 225-236. doi: 10.1016/S0167-7012(98) 00014-1.

Zimmerman, R. \& Meyer-Reil, L. (1974). A new method for fluorescence staining of bacterial populations on membrane filters. Kiel. Meeresforsch, 30, 24-27.

Zweifel, U. L. \& Hagström, A. (1995). Total counts of marine bacteria include a large fraction of non-nucleoid-containing bacteria (ghosts). Applied and Environmental Microbiology, 61, 2180-2185.
Key References

Barbesti et al., 2000. See above.

The original presentation of the NADS protocol.

Grégori et al., 2001. See above.

This article describes the adaptation of the NADS protocol described by Barbesti et al. (2000) to natural fresh and marine water samples.

\section{Internet Resources}

https://www.probes.com/servlets/pis

This Web site displays technical bulletins on Molecular Probes fluorochromes with useful storage and handling information and suggestions for their use. 